\title{
Analisis Stabilitas Dan DURABILITAS CAMPURAN Pada ASPal Modifikasi Menggunakan Polimer LDPE
}

\author{
Indah Handayasari ${ }^{1}$; Dyah Pratiwi Kusumastuti ${ }^{2}$; Arief Suardi Nur Chairat ${ }^{3}$ \\ ${ }^{1}$ Institut Teknologi PLN \\ ${ }^{2}$ Institut Teknologi PLN \\ ${ }^{3}$ Institut Teknologi PLN \\ Indah.handayasari@itpln.ac.id
}

\begin{abstract}
One of the efforts to produce asphalt that has a high level of durability is to modify asphalt by utilizing synthetic polymers as a mixture. Polymers are able to increase the level of pavement durability from various kinds of damage, such as permanent deformation, cracking due to temperature changes, material damage, and material release. Testing the resistance of the AC-WC mixture using crackle plastic type LDPE (Low density polyethylene) polymer against water through immersion in water at a temperature of $600 \mathrm{C}$ for 30 minutes, 24 hours, 48 hours and 72 hours with a continuous system and variations of LDPE plastic bag waste are planned at 0\%, 1\%, 3\%, 5\%, 7\%, 9\% and 11\%. Based on the results of the study, it was found that the highest stability value after continuous immersion was found in variations in the levels of 5\% LDPE plastic bag waste, which was $965,360 \mathrm{~kg}$ with a durability value or residual strength index of $92.46 \%$ at soaking for 72 hours.
\end{abstract}

Keywords: Stability, Durability, Polymer

\begin{abstract}
Abstrak
Salah satu upaya dalam menghasilkan aspal yang memiliki tingkat keawetan yang tinggi yaitu memodifikasi aspal dengan memanfaatkan polimer sintetis sebagai bahan campuran. Polimer mampu menambah tingkat durabilitas perkerasan dari berbagai macam kerusakan, seperti deformasi permanen, retak akibat perubahan temperatur, kerusakan material, serta pelepasan material. Pengujian ketahanan campuran AC-WC menggunakan plastik kresek jenis polimer LDPE (Low density polyethylene) terhadap air melalui perendaman dalam air bertemperatur $60 \mathrm{oC}$ selama 30 menit, 24 jam, 48 jam dan 72 jam dengan sistem menerus serta variasi limbah kantong plastik LDPE direncanakan sebesar 0\%, 1\%, 3\%, 5\%, 7\%, 9\% dan $11 \%$. Berdasarkan hasil penelitian didapatkan bahwa nilai stabilitas tertinggi setelah dilakukan perendaman secara menerus terdapat pada variasi kadar limbah kantong plastik LDPE 5\% yaitu sebesar 965,360kg dengan nilai durabilitas atau indeks kekuatan sisa sebesar 92,46\% pada perendaman selama 72 jam.
\end{abstract}

Kata kunci: Stabilitas, Durabilitas, Polimer

\section{A. PENDAHULUAN}

Jalan raya merupakan salah satu prasaranan transportasi yang mempunyai peran yang sangat penting sebagai penggerak perekonomian. Hal ini mengingat jalan raya menjadi pendukung berbagai kegiatan distribusi bahan pangan, kegiatan sosial, bisnis, pendidikan, pengembangan wilayah dan lainnya. Oleh sebab itu, sangatlah diperlukan jalan yang memiliki kekuatan, keawetan serta mampu menahan keausan akibat pengaruh cuaca dan iklim maupun perubahan temperatur. Selain itu juga diharapkan bahwa jalan yang dibangun mengeluarkan biaya yang ekonomis dalam pengerjaannnya sehingga dapat dihasilkan jalan yang memiliki kemampuan memikul beban lalu lintas dengan biaya yang relatif murah namun tetap memenuhi persyaratan yang ditentukan. 
Untuk meghasilkan jalan dengan kualitas yang baik dan bernilai ekonomis telah dilakukan berbagai inovasi material campuran beraspal yang memanfaatkan polimer sebagai alternatif bahan tambah atau substitusi. Menurut Sumiati et al., 2019 dengan memodifikasi aspal menggunakan polimer pada campuran aspal menunjukkan hasil bahwa polimer dapat digunakan dan memberikan nilai durabilitas yang baik sehingga tahan terhadap cuaca ekstrem. Hasil pengujian yang di lakukan oleh Susanto \& Suaryana, 2019 dengan aspal modifikasi menggunakan polimer memberikan peningkatan nilai stabilitas campuran yaitu dari nilai sebesar $1100 \mathrm{~kg}$ menjadi $1400 \mathrm{~kg}-1500 \mathrm{~kg}$.

Seiring dengan penanganan perbaikan campuran aspal yang memanfaatkan polimer sebagai alternatif bahan perkuatan, salah satu polimer yang banyak dijumpai dan merupakan limbah yaitu kantong plastik. Limbah kantong plastik ini adalah polimer jenis LDPE (Low density polyethylene) yang selain harganya murah dikarenakan kantong plastik yang digunakan merupakan limbah dan tidak terpakai lagi akan tetapi diharapkan juga tetap dapat memperbaiki nilai stabilitas dan durabilitas pada campuran AC-WC yang direncanakan. Pemanfaatan limbah kantong plastik sendiri juga dapat menjadi salah satu cara dalam menanggulangi permasalahan kerusakan lingkungan. Hal ini mengingat data Kementrian Lingkungan Hidup dan Kehutanan (KLHK) menujukkan bahwa jumIah sampah plastik mencapai 9,52 juta ton atau sebesar 14\% dari jumlah sampah yang ada, sehingga dengan pemanfaatan limbah kantong plastik sebagai alternatif bahan tambah pada campuran beraspal dapat berdampak baik pada perbaikan lingkungan.

\section{B. METODE/PERANCANGAN PENELITIAN}

\section{Perkerasan Lentur (Flexible Pavement)}

Aspal berfungsi sebagai bahan pengikat pada perkerasan jalan lentur. Aspal merupakan material semen yang berwarna hitam, memiliki tekstur padat atau setengah padat. Umumnya, jenis aspal yang digunakan di Indonesia adalah jenis aspal dengan penetrasi 60/70 atau dengan penetrasi 80/100. Jenis ini lebih cocok dengan iklim di Indonesia. Dalam penggunaannya, aspal dipanaskan terlebih dahulu sampai pada temperatur tertentu hingga aspal menjadi cair. Dalam keadaan cair, aspal bisa membungkus partikel agregat dan dapat masuk ke pori-pori lapisan jalan. Saat temperaturnya sudah mulai turun, aspal akan menjadi keras lalu mengikat agregat di tempatnya.

\section{Stabilitas}

Stabilitas adalah kemampuan perkerasan jalan untuk tidak mengalami deformasi berlebihan selama melayani kendaraan yang lewat. Stabilitas campuran tergantung pada gaya gesek internal dan kohesitas. Gaya gesek antar butir-butir agregat berhubungan dengan sifat agregat seperti gradasi, bentuk dan tekstur permukaan, sedangkan kohesitas merupakan gaya ikat yang di miliki aspal dan di pengaruhi oleh tipe dan jumlah bahan pengisi yang di tambahkan. Daya ikat dan gaya gesek akan menahan perpindahan antar butiran agregat akibat beban lalu lintas.

\section{Durabilitas}

Durabilitas adalah kemampuan atau daya tahan suatu perkerasan terhadap beberapa faktor seperti perubahan-perubahan dalam bitumen yang di sebabkan oleh oksidasi, disintegrasi agregat, dan pelepasan lapisan-lapisan bitumen dari agregat akibat kondisi basah 
dan beban lalu lintas. Durabilitas berkaitan dengan keawetan campuran terhadap pengaruh air dan temperatur dalam waktu lama. Salah satu parameter kinerja campuran beton aspal adalah ketahanan (durability). Untuk mendapatkan durabilitas yang baik biasanya digunakan kadar aspal yang tinggi. Namun apabila campuran aspal dengan kadar aspal yang tinggi tersebut selalu terendam air maka lambat laun jalan akan mengalami kerusakan. Metode yang digunakan dalam mengevaluasi pengaruh air terhadap campuran beraspal dengan pengujian perendaman Marshall yang mana stabilitas benda uji ditentukan dengan perendaman di dalam air pada suhu $60^{\circ} \mathrm{C}$. Perbandingan stabilitas yang direndam dengan stabilitas standar dinyatakan dalam persen.

\section{Tahapan Penelitian}

Material utama yang digunakan dalam penelitian ini adalah aspal penetrasi 60/70, agregat kasar, agregat halus, filler semen portland serta bahan tambah limbah polimer jenis LDPE (Low density polyethylene) terhadap campuran beraspal. Penelitian ini menggunakan pendekatan uji skala laboratorium dengan melakukan pengujian ketahanan campuran ACWC melalui perendaman dalam air bertemperatur $60^{\circ} \mathrm{C}$ selama 30 menit, 24 jam, 48 jam dan 72 jam dengan sistem menerus serta penentuan parameter evaluasi kekuatan setelah benda uji direndam atau indeks kekuatan sisa. Setelah dilakukan pendataan dilaboratorium, pengelolaan data dan analisis berdasarkan data yang telah diperoleh sehingga didapatkan hasil pemecahan masalah yang efektif dan terarah.

\section{HASIL DAN PEMBAHASAN}

Berdasarkan hasil pengujian terhadap pencampuran bahan tambah polimer jenis LDPE (Low density polyethylene) menujukkan bahwa nilai stabilitas didapatkan dapat memenuhi syarat batas nilai $\geq 800 \mathrm{~kg}$ sebagai berikut :

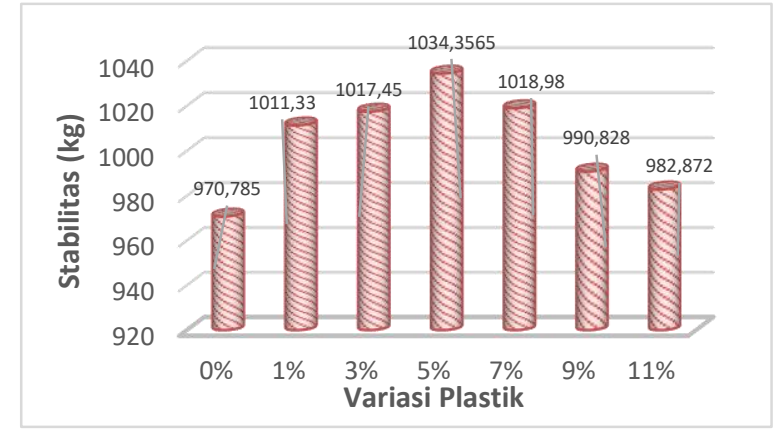

(a) Perendaman 30 menit

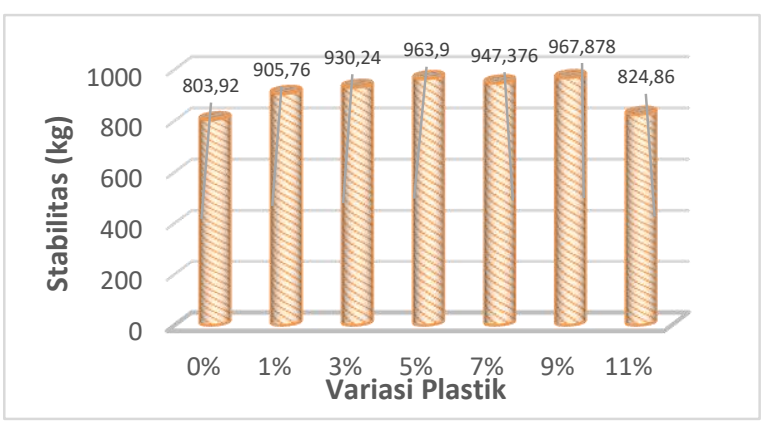

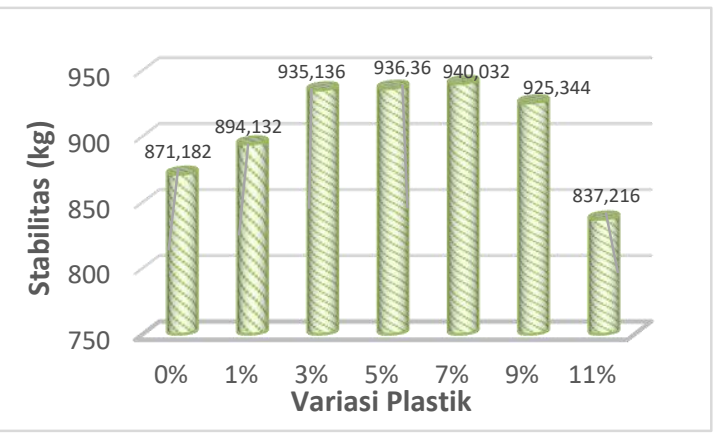

(b) Perendaman 24 Jam

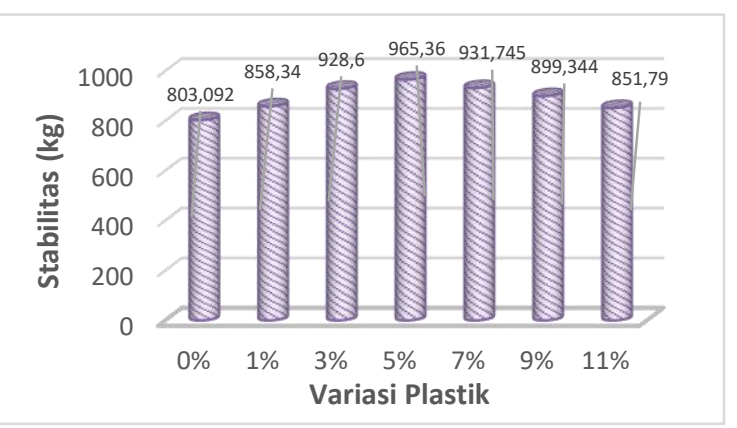


(c) Perendaman 48 Jam

(d) Perendaman 72 Jam

Gambar 1. Nilai Stabilitas

Hasil pengujian ketahanan campuran AC-WC dengan penambahan variasi kadar kantong plastik jenis polimer LDPE yang dimana benda uji direndam dalam air bertemperatur $60^{\circ} \mathrm{C}$ dengan durasi perendaman selama 24 jam, 48 jam, dan 72 jam dapat dilihat pada tabel dibawah ini :

Tabel 1. Hasil Pengujian Durabilitas atau Indeks Kekuatan Sisa (Perendaman 24 Jam)

\begin{tabular}{|c|c|c|c|c|c|c|}
\hline No & $\begin{array}{l}\text { Kadar } \\
\text { Plastik }\end{array}$ & $\begin{array}{c}\text { Stabilitas } \\
\text { Rendaman } 30 \\
\text { Menit } \\
(\mathrm{kg})\end{array}$ & $\begin{array}{c}\text { Stabilitas } \\
\text { Rendaman } \\
\text { 24 Jam } \\
(\mathrm{kg})\end{array}$ & $\begin{array}{c}\text { Nilai } \\
\text { Durabilitas } \\
\text { atau IKS } \\
(\%)\end{array}$ & $\begin{array}{c}\text { Syarat } \\
(\%)\end{array}$ & Keterangan \\
\hline $\mathrm{a}$ & b & $\mathrm{c}$ & d & $\mathrm{e}=(\mathrm{d} / \mathrm{c}) \times 100$ & \multirow{6}{*}{$\geq 90$} & \\
\hline 1 & $0 \%$ & 970,791 & 890,239 & 91,70 & & Terpenuhi \\
\hline 2 & $1 \%$ & 1011,332 & 914,132 & 90,38 & & Terpenuhi \\
\hline 3 & $3 \%$ & 1017,452 & 935,136 & 91,91 & & Terpenuhi \\
\hline 4 & $5 \%$ & 1034,356 & 986,362 & 95,36 & & Terpenuhi \\
\hline 5 & $7 \%$ & 1018,982 & 948,602 & 93,09 & & Terpenuhi \\
\hline 6 & $9 \%$ & 990.828 & 919,201 & 92,77 & & Terpenuhi \\
\hline 7 & $11 \%$ & 982,872 & 837,216 & 85,18 & & Tidak Terpenuhi \\
\hline
\end{tabular}

Tabel 2. Hasil Pengujian Durabilitas atau Indeks Kekuatan Sisa (Perendaman 48 Jam)

\begin{tabular}{|c|c|c|c|c|c|c|}
\hline No & $\begin{array}{l}\text { Kadar } \\
\text { Plastik }\end{array}$ & $\begin{array}{c}\text { Stabilitas } \\
\text { Rendaman } \\
30 \text { Menit } \\
(\mathrm{kg})\end{array}$ & $\begin{array}{c}\text { Stabilitas } \\
\text { Rendaman } \\
\text { 48 Jam } \\
(\mathrm{kg})\end{array}$ & $\begin{array}{c}\text { Nilai } \\
\text { Durabilitas } \\
\text { atau IKS } \\
(\%)\end{array}$ & $\begin{array}{c}\text { Syarat } \\
(\%)\end{array}$ & Keterangan \\
\hline $\mathrm{a}$ & $\mathrm{b}$ & $\mathrm{c}$ & d & $e=(d / c) \times 100$ & \multirow{6}{*}{$\geq 90$} & \\
\hline 1 & $0 \%$ & 970,791 & 871,182 & 89,74 & & $\begin{array}{l}\text { Tidak } \\
\text { Terpenuhi }\end{array}$ \\
\hline 2 & $1 \%$ & 1011,332 & 905,76 & 89,56 & & $\begin{array}{l}\text { Tidak } \\
\text { Terpenuhi }\end{array}$ \\
\hline 3 & $3 \%$ & 1017,452 & 930,24 & 91,43 & & Terpenuhi \\
\hline 4 & $5 \%$ & 1034,356 & 963,901 & 93,19 & & Terpenuhi \\
\hline 5 & $7 \%$ & 1018,982 & 940,032 & 92,25 & & Terpenuhi \\
\hline 6 & $9 \%$ & 990.828 & 907,878 & 91,63 & & Terpenuhi \\
\hline 7 & $11 \%$ & 982,872 & 824,86 & 83,92 & & $\begin{array}{l}\text { Tidak } \\
\text { Terpenuhi }\end{array}$ \\
\hline
\end{tabular}


Tabel 3. Hasil Pengujian Durabilitas atau Indeks Kekuatan Sisa (Perendaman 72 Jam)

\begin{tabular}{|c|c|c|c|c|c|c|}
\hline No & $\begin{array}{l}\text { Kadar } \\
\text { Plastik }\end{array}$ & $\begin{array}{c}\text { Stabilitas } \\
\text { Rendaman } \\
30 \text { Menit } \\
(\mathrm{kg}) \\
\end{array}$ & $\begin{array}{c}\text { Stabilitas } \\
\text { Rendaman } \\
72 \text { Jam } \\
(\mathrm{kg}) \\
\end{array}$ & $\begin{array}{c}\text { Nilai } \\
\text { Durabilitas } \\
\text { atau IKS } \\
(\%)\end{array}$ & $\begin{array}{c}\text { Syarat } \\
(\%)\end{array}$ & Keterangan \\
\hline $\mathrm{a}$ & $\mathrm{b}$ & $\mathrm{c}$ & d & $\mathrm{e}=(\mathrm{d} / \mathrm{c}) \times 100$ & \multirow{6}{*}{$\geq 90$} & \\
\hline 1 & $0 \%$ & 970,791 & 803,092 & 82,73 & & $\begin{array}{l}\text { Tidak } \\
\text { Terpenuhi }\end{array}$ \\
\hline 2 & $1 \%$ & 1011,332 & 858,34 & 84,87 & & $\begin{array}{l}\text { Tidak } \\
\text { Terpenuhi }\end{array}$ \\
\hline 3 & $3 \%$ & 1017,452 & 928,60 & 91,24 & & Terpenuhi \\
\hline 4 & $5 \%$ & 1034,356 & 965,360 & 92,46 & & Terpenuhi \\
\hline 5 & $7 \%$ & 1018,982 & 931,745 & 91.44 & & Terpenuhi \\
\hline 6 & $9 \%$ & 990.828 & 899,344 & 90,76 & & Terpenuhi \\
\hline 7 & $11 \%$ & 982,872 & 851,79 & 86,66 & & $\begin{array}{l}\text { Tidak } \\
\text { Terpenuhi }\end{array}$ \\
\hline
\end{tabular}

Berdasarkan Spesifikasi Bina Marga 2018 syarat untuk nilai durabilitas atau indeks kekuatan sisa untuk melihat kewetan campuran aspal adalah minimal 90\%. Jika nilai nilai tersebut tidak terpenuhi maka jalannya air untuk masuk kedalam lapisan aspal akan semakin mudah dan hal tersebut akan menyebabkan sifat interlocking dalam aspal akan berkurang. Hasil pengujian menunjukan untuk perendaman 24 jam nilai stabilitas tertinggi pada campuran aspal dengan varias kadar kantong plastik LDPE sebesar 5\% dan nilai durabilitas atau indeks kekuatan sisa memenuhi syarat yang ditentukan yaitu sebesar 95,36\%. Untuk perendaman 48 jam nilai stabilitas tertinggi pada campuran aspal dengan varias kadar kantong plastik LDPE sebesar 5\% dan nilai durabilitas indeks kekuatan sisa memenuhi syarat yang ditentukan yaitu sebesar $93,19 \%$. Untuk perendaman 72 jam nilai stabilitas tertinggi pada campuran aspal dengan varias kadar kantong plastik LDPE sebesar 5\% dan nilai durabilitas indeks kekuatan sisa memenuhi syarat yang ditentukan yaitu sebesar 92,46\%. Sedangkan untuk nilai durabilitas atau indeks kekuatan sisa variasi kadar kantong plastik LDPE sebesar $0 \%, 1 \%$, dan $11 \%$ pada perendaman 48 jam dan 72 jam tidak memenuhi persyaratan yang ditentukan. Berdasarkan analisis dari hasil pengujian dapat disimpulkan bahwa penambahan plastik jenis polimer LDPE dapat meningkatkan stabilitas campuran AC-WC. Penggunaan plastik polimer LDPE pada campuran AC-WC dapat meningkatkan ketahanan terhadap kerusakan campuran akibat rendaman air secara menerus yaitu mengurangi nilai Index Retained Strength dan meningkatkan nilai indeks kekuatan tersisa dengan bertambahnya lama durasi perendaman. 


\section{KESIMPULAN DAN SARAN}

Secara umun simpulan pada penelitian ini yaitu nilai indeks kekuatan sisa yang dihasilkan dapat menjadi gambaran ketahanan aspal modifikasi dengan bahan tambah limbah kantong plastik LDPE dalam campuran AC-WC. Penambahan limbah kantong plastik pada campuran aspal akan menambah tingkat ketahan dan memperpanjang daya layan aspal.

\section{UCAPAN TERIMAKASIH}

Ucapan terima kasih kami tujukan kepada LPPM Institut Teknologi PLN yang telah memfasilitasi penelitian ini dalam skema pendanaan Penelitian Unggulan Tahun Ajaran 2020/2021 serta semua pihak yang ikut membantu pada proses pelaksanaan penelitinan maupun penyusunan naskah jurnal.

\section{REFERENSI}

1. Atkins, H. (2002). Highway Materials, Soils,And Concretes (4th ed.). Prentice Hall.

2. Bina Marga. (2018). Spesifikasi Umum Bina Marga 2018 untuk Pekerjaan Jalan dan Jembatan (General Specifications of Bina Marga 2018 for Road Works and Bridges). September

3. Craus, J., Ishai, I., and Sides, A.,(1981), "Durability of Bituminous Paving Mixtures as Related to Filler Type and Propertis "Proceedings Association of Asphalt Paving Technologists, Technicalsessions, February 16,17 and 18, Volume. 50, San diego, California..

4. Fithra, H. (2018). Hubungan Antara Konsistensi Perancangan, Pelaksanaan dan Pengendalian Mutu Aspal terhadap Penurunan Kinerja Jalan (Edisi Revisi). Unimal Press.

5. Fitri, S., Saleh, S. M., \& Isya, M. (2018). Pengaruh Penambahan Limbah Plastik Kresek Sebagai Substitusis Aspal Pen 60/70 Terhadap Karakteristik Campuran Laston AC BC. Jurnal Teknik Sipil. https://doi.org/10.24815/jts.v1i3.10034

6. Harnaeni, S.R, Pramesti, F.P., Budiarto, A., dan Setyawan, A. (2018). A Preliminary Study of

7. Mechanistic Approach in Pavement Design to Accommodate Climate Change Effects.

8. IOP Conference Series: Earth and Environmental Science, 129 (1).

9. Kosasih, \& Agus. (1997). Kontrol Kepadatan dalam Pengujian Marshall. Teknik Sipil.

10. Marga, B. (2010). Spesifikasi Umum 2010 (revisi 3). Direktorat Jendral Kementrian Pekerjaan Umum.

11. Nahyo, Sudarno \& Bagus, H. S. (2015), Durabilitas Campuran Hot Rolled SheetWearing (HFS-WC) Akibat Rendaman Menerus dan Berkala Air Rob, Jurnal Teknik Sipil, Vol 13 No.1, 124-135. DOI: https://doi.org/10.30601/jtsu.v1i2.14 
12. Polacco, G., Berlincioni, S., Biondi, D., Stastna, J., \& Zanzotto, L. (2005). Asphalt Modification with Different Polyethylene-Based Polymers. European Polymer Journal, 41(12), 2831-2844. https://doi.org/10.1016/j.eurpolymj.2005.05.034

13. Pratama, N. Y., Widodo, S., \& Sulandari, E. (2018). Pengaruh Penggunaan Sampah Botol Plastik Sebagai Bahan Tambah pada Campuran Lapis Aspal Beton (LASTON).

14. Puslitbang. (2014). Pusat Penelitian Bangunan Jalan dan Jembatan. Puslitbang.

15. Saodang, H. (2005). Perancangan Perkerasan Jalan Raya. Nova..

16. Sumiati, Mahmuda, \& Syapawi, A. (2019). Perkerasan Aspal Beton (AC-BC) Limbah Plastik

17. HDPE yang Tahan Terhadap Cuaca Ekstrem. Cam, 1 .

18. Susanto, I., \& Suaryana, N. (2019). Evaluasi Kinerja Campuran Beraspal Lapis Aus (AC-WC) dengan Bahan Tambah Limbah Plastik Kresek. Jurnal Aplikasi Teknik Sipil. https://doi.org/10.12962/j2579-891x.v17i2.4980

19. Sulistiyatno, A., Fajri, M.D.S.R., Mochtar, I.S., Kartika, A.A.G., dan Mulyana, M.A. (2012). Studi Pengaruh Genangan Air terhadap Kerusakan Jalan Aspal dan Perencanaan Subdrain untuk Ruas Jalan Rungkut Industri Raya, Jalan Rungkut Kidul Raya, Jalan Jemur Sari, Jalan Nginden Raya, Jalan Manyar, dan Jalan Mulyosari Raya. Jurnal Teknik POMITS, 1 (1): 1-6.

20. Yildirim, Y. (2007). Polymer Modified Asphalt Binders. Construction and Building Materials. https://doi.org/10.1016/j.conbuildmat.2005.07.007 